University of Nebraska - Lincoln

DigitalCommons@University of Nebraska - Lincoln

$7-1-2002$

\title{
Effect of Time of Temperature Observation and Estimation of Daily Solar Radiation for the Northern Great Plains, USA
}

\author{
Rezaul Mahmood \\ Western Kentucky University, rmahmood2@unl.edu \\ Kenneth Hubbard \\ University of Nebraska-Lincoln, khubbard1@unl.edu
}

Follow this and additional works at: https://digitalcommons.unl.edu/natrespapers

Part of the Natural Resources and Conservation Commons

Mahmood, Rezaul and Hubbard, Kenneth, "Effect of Time of Temperature Observation and Estimation of Daily Solar Radiation for the Northern Great Plains, USA" (2002). Papers in Natural Resources. 39.

https://digitalcommons.unl.edu/natrespapers/39

This Article is brought to you for free and open access by the Natural Resources, School of at DigitalCommons@University of Nebraska - Lincoln. It has been accepted for inclusion in Papers in Natural Resources by an authorized administrator of DigitalCommons@University of Nebraska - Lincoln. 


\title{
Agronomy Journal
}

Volume 94

July-August 2002

Number 4

\section{MODELING}

\section{Effect of Time of Temperature Observation and Estimation of Daily Solar Radiation for the Northern Great Plains, USA}

\author{
Rezaul Mahmood* and Kenneth G. Hubbard
}

\begin{abstract}
Daily incident solar radiation is an important input for numerous crop growth simulation models. However, lack of recorded solar radiation is a significant impediment for most crop-climate studies. The present study aimed to overcome the problem of sparse historical data of solar radiation over the northern Great Plains. The approach was to develop a physically based solar radiation model wherein estimates were possible with minimum input data. In addition, this study investigates impacts of time of observation bias on the model formulation. The proposed model (M-H) requires measured daily range of air temperature (maximum minus minimum) and estimated daily clearsky solar radiation. Daily weather data (including solar radiation measurements) for nine stations with observations from 1990 through 1998 were used for formulation of the final model. To determine potential bias associated with the reporting time, three times- $-0800,1600$, and $2400 \mathrm{~h}$-were tested. Based on superior performance, the solar radiation model formulated with 2400-h reporting time data from Akron, CO, was selected for the whole region. The model underestimated high values. Local-scale advection and frontal passage were apparently responsible for this bias. This proposed model was also compared with two forms of the Bristow-Campbell (B-C) model. Both of these forms show significant improvement for 2400 -h observation time. One particular form of the B-C model performs slightly better than the model proposed here. However, it also underestimates high values like the M-H model and shows slight regional bias. This study finds that, overall, the M-H model is more stable than the B-C model.
\end{abstract}

\begin{abstract}
$\mathrm{A}^{\mathrm{N}}$ NUMBER OF CROP GROWTH simulation models are currently available to assess crop vulnerability, risk management, decision strategies, and policy-making, with the goal of minimizing crop loss in the future (cf., Easterling et al., 1993). Models can also be applied to predict future crop yield under variable weather and

R. Mahmood, Dep. of Geogr. and Geol. and Kentucky Climate Cent., Western Kentucky Univ., Bowling Green, KY 42101; and K.G. Hubbard, High Plains Regional Climate Cent., 242 L W. Chase Hall, School of Nat. Resour. Sci., Univ. of Nebraska, Lincoln, NE 68583-0728. Publ. as Journal Ser. no. 13043, Agric. Res. Div., Univ. of Nebraska-Lincoln. Received 2 June 2000. *Corresponding author (Rezaul.Mahmood@ wku.edu).
\end{abstract}

Published in Agron. J. 94:723-733 (2002). climate conditions (cf., Rosenzweig and Parry, 1994; Mahmood and Hayes, 1995; Mearns et al., 1996). Daily solar radiation is one key input to these models. However, in the USA, as in many other countries of the world, availability of daily solar radiation data is limited, and a ratio between stations observing solar radiation and temperature is approximately 1:100 (Natl. Climatic Data Cent., 1995). To address this problem, numerous methods were developed to estimate solar radiation (e.g., Cengiz et al., 1981; Bristow and Campbell, 1984; Hunt et al., 1998; Goodin et al., 1999; McVicar and Jupp, 1999; Thornton and Running, 1999). Moreover, data requirements and complexity associated with some of these solar radiation models prevented their application across a wide range of climate (cf., Atwater and Ball, 1978; Hook and McClendon, 1992; Dissing and Wendler, 1998).

These methods did not address the impact of time of observation bias (TOB) on model parameter formulation. (Observation time and reporting time will be used interchangeably in this paper.) A number of studies indicated that bias introduced in the recorded data due to observation time is a notable problem for any type of detailed climate study (Baker, 1975; Schaal and Dale, 1977; Winkler et al., 1981; Blackburn, 1983; Karl et al., 1986; DeGaetano, 1999; Janis, 2000). The voluntary nature of the Cooperative Observer Network is the primary cause of inducing TOB. Volunteers usually record observations of daily maximum and minimum air temperature at a time that is convenient for them. The most common observation times are 0600 to $0800 \mathrm{~h}$ or 1600 to $1900 \mathrm{~h}$ local time. Thus, reporting time can vary from station to station. Moreover, change of observer can also complicate this situation as the new observer may report daily extremes at a different time from their predecessor. This type of inconsistency in reporting time

Abbreviations: B-C, Bristow-Campbell model; DOY, day of year; DR, range of daily air temperature (maximum minus minimum); ICSKY, corrected clear-sky solar radiation; $\mathrm{M}-\mathrm{H}$, Mahmood-Hubbard model; NGP, northern Great Plains; RMSE, root mean square error; TOB, time of observation bias; $Y_{\text {mod }}$, estimated solar radiation (corrected for systematic bias). 
introduces both temporal and spatial inhomogeneity (Janis, 2000). DeGaetano (1999) noted that nonclimatic bias is introduced in the temperature time series due to changes in observation time. Another type of network, first-order weather stations, maintains a midnight-tomidnight reporting time. These stations are well maintained and, before automation, were staffed continuously. It is found that the greatest positive and negative bias occurs when the time of observation falls near the time of normal maximum and minimum air temperature occurrence, respectively (Winkler et al., 1981). DeGaetano (1999) suggested that stations whose observation time is close to the occurrence of daily maximum air temperature would show a warm bias, and those close to the occurrence of the daily minimum would show a cold bias. In short, it is clear that TOB is a significant problem and can considerably reduce accuracy of climatic studies.

In response to these concerns and restrictions, we are presenting a daily solar radiation estimation method (M-H, hereafter) that requires minimum input data and addresses the impacts of TOB on model formulation and accuracy. Our method to estimate solar radiation uses the daily maximum and minimum air temperature data and estimated clear-sky solar radiation (based on Cengiz et al., 1981) as inputs. The use of maximum and minimum air temperature data associated with an observation time that results in a date different from the date of occurrence will lead to disassociation between air temperature and the solar radiation to be estimated. Consequently, we study the effect of time of air temperature observations. In addition, the $\mathrm{M}-\mathrm{H}$ model accuracy is compared to the performance of the two versions of the Bristow and Campbell (B-C, hereafter) method (Bristow and Campbell, 1984), developed by Goodin et al. (1999). These two versions of the models are also based on the relationship between daily air temperature range (DR) and solar radiation. Impacts of TOB on the performance of these two versions of the B-C method are also evaluated in this study.

It is assumed that daily incident solar radiation at a fixed height and on a horizontal surface during a clear day is largely a function of clear-sky solar radiation. On the other hand, during a cloudy day, solar radiation received at the earth's surface is less compared with a clear day. Since daily surface and near-surface thermal conditions are largely driven by solar radiation received at the surface, maximum and minimum air temperatures are a good indicator of cloudiness and resultant incident solar radiation (Bristow and Campbell, 1984). Humidity, along with cloudiness, also influences air temperatures. The DR is generally higher on clear days and lower under clouded sky (e.g., Cengiz et al., 1981). Therefore, in this method, DR surrogates as an index of cloudiness and humidity (Cengiz et al., 1981; Clemence, 1992).

The M-H model includes physical explanation, its performance was evaluated under a variety of conditions in the northern Great Plains (NGP) (used data from nine sites) using a time series containing 9 yr of daily data, and has a built-in approach to overcome errors associated with observation time. As opposed to the M-H model, for example, the B-C (Bristow and Campbell, 1984) method was developed using only $1 \mathrm{yr}$ of data, and its performance was evaluated based on its application to only two sites. Latitudinal extent of their two sites is less than $1^{\circ}$. Recently, recalibrated and reformulated B-C methods have been presented by Goodin et al. (1999). They have developed their model parameters using $30 \mathrm{yr}$ of data from one station at Manhattan, KS. The performance of these models (Goodin et al., 1999) was evaluated based on their application to 10 sites in Kansas. Again, latitudinal extent and variations in site climate characteristics for the application of the modified B-C model (Goodin et al., 1999) to evaluate its performance is far more restricted compared with the model presented here.

In contrast to these studies (Bristow and Campbell, 1984; Goodin et al., 1999), McVicar and Jupp (1999) successfully applied the B-C method to much larger areas in Australia and China. They developed coefficients for the B-C method that are suitable for large agricultural areas. Nevertheless, potential impacts of reporting time on the model formulation and on the accuracy of solar radiation estimates were not addressed by the $\mathrm{B}-\mathrm{C}$ (Bristow and Campbell, 1984) model and by the recalibrated and the modified B-C models (Goodin et al., 1999; McVicar and Jupp, 1999). However, the B-C model requires minimum data and has shown promise in estimating solar radiation. Therefore, two versions of the B-C model (Goodin et al., 1999) are also tested and compared to the method presented in this study. The unmodified-recalibrated $\mathrm{B}-\mathrm{C}$ method with original formulation approach and the modified B-C model proposed by Goodin et al. (1999) are quite suitable for this study because they were developed in the NGP. As a result, this study also uses coefficients estimated by Goodin et al. (1999). As noted above, the aim of this study is to present a model for estimating solar radiation that would help to overcome the problem of sparseness of data and also show TOB in the estimation. The discussion in the following sections will compare the performance of the solar radiation estimation model presented in this paper with that of the B-C methods proposed by Goodin et al. (1999).

\section{MATERIALS AND METHODS}

The model (M-H) proposed in this study can be expressed as follows:

$$
Y=\mathrm{f}(\mathrm{DR}, \mathrm{ICSKY})
$$

where $Y$ is estimated solar radiation and ICSKY is corrected clear-sky solar radiation. The formulation of the model and its coefficients are provided below. Observed daily solar radiation and daily maximum and minimum air temperature data were available from nine automated weather stations (Fig. 1). These stations are part of the Automated Weather Data Network of the NGP (Hubbard et al., 1983). This network is a collaborative effort between the state climate offices of the region and the High Plains Regional Climate Center. This network records and archives hourly data and maintains a midnightto-midnight (2400-2400 h) reporting time. For this study, two additional reporting times are assumed to identify the potential impacts of observation time on the accuracy of the model. 
These are 0800 and $1600 \mathrm{~h}$ where maximum and minimum air temperatures reported are the extremes of the previous $24 \mathrm{~h}$. RH207 and Vaisala thermistor thermometers have been used to record air temperature from 1990 to 1991 and 1992 to 1998, respectively. These two instruments are interchangeable within $1{ }^{\circ} \mathrm{C}$ accuracy. The sensors are calibrated annually between spring and summer. A quality control procedure notifies data managers of potential data problems so that corrective action can be taken. The quality control program is applied daily. Solar radiation is measured by a LI-COR pyranometer. Pyranomters are also calibrated annually, again, between spring and summer (Aceves-Navarro et al., 1989). The horizontal level is checked during installation and site visits. Rain keeps the instruments clean. Site visits (repair and maintenance) occur when the quality control program indicates a problem with the data. The data used in this study can be acquired online from the High Plains Regional Climate Center (http://hpccsun.unl.edu; verified 16 Apr. 2002).

This study assumes clear-sky solar radiation is a function of latitude and day of year (DOY). This relationship is expressed by Cengiz et al. (1981) as follows:

$I_{\mathrm{S}}=0.04188\{A+B \sin [2 \pi(d+10.5) / 365-(\pi / 2)]\} \quad[2]$

where $I_{\mathrm{S}}$ is clear-day solar radiation $\left(\mathrm{MJ} \mathrm{m}^{-2} \mathrm{~d}^{-1}\right), d$ is DOY, and $A$ and $B$ are constants. These can be estimated as follows (after Cengiz et al., 1981):

$$
\begin{aligned}
A= & \{\sin \phi(46.355 \times \mathrm{LD}-574.3885) \\
& +816.41 \cos \phi \sin [(\pi \times \mathrm{LD}) / 24]\} \\
& (0.29 \cos \phi+0.52) \\
B= & {[\sin \phi(574.3885-1.509 \times \mathrm{LD})} \\
& -26.59 \cos \phi \sin [(\pi \times \mathrm{LD}) / 24)] \\
& (0.29 \cos \phi+0.52)
\end{aligned}
$$

where $\phi$ is latitude and LD is longest DOY (h). LD can be estimated from:

$$
\begin{aligned}
\mathrm{LD}= & 0.267 \sin ^{-1}[0.5+(0.007895 / \cos \phi) \\
& +(0.2168875 \tan \phi)]^{0.5}
\end{aligned}
$$

The expression presented in Eq. [5] is obtained from the Tables of Sunrise, Sunset and Twilight (U.S. Naval Observatory, 1946). Subsequently, a correction for atmospheric transmissivity is introduced to determine final daily clear-sky solar radiation. An empirical transmissivity correction function was derived from a comparison of calculated clear-sky solar radiation and measured values at the earth's surface:

$$
T=0.8+0.12 \times(c)^{1.5} \quad c=|182-d| / 183
$$

where $T$ is transmissivity coefficient for the M-H model. The coefficients for effective transmissivity correction functions were developed through a number of trials for three sites including Garden City, KS; Champion, NE; and Fargo, ND. During the development phase, these coefficients were used within List's (1951, p. 420) framework to estimate clear-sky radiation. It was found that transmissivity correction with these coefficients provides clear-sky radiation comparable to highest measured radiation at the three sites. In the present model, transmissivity is a function of DOY. For example, the transmissivity correction function for 21 December (DOY 355 ) is 0.91 while for 20 June (DOY 171), it is 0.80. Finally,

$$
\mathrm{ICSKY}=T \times I_{\mathrm{S}}
$$

The unmodified-recalibrated B-C model is expressed by Goodin et al. (1999) as follows:

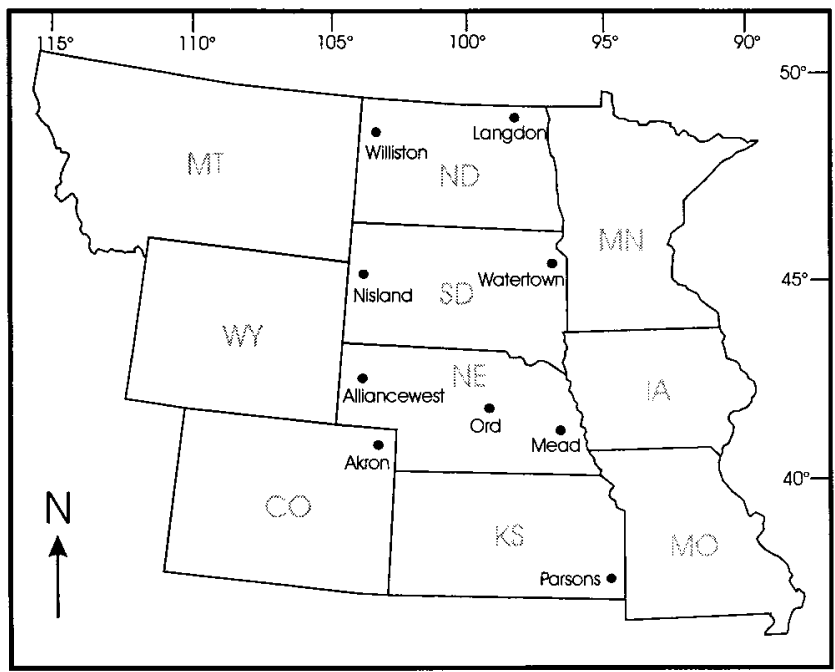

Fig. 1. Location of meteorological stations.

$$
T_{\mathrm{t}}=R_{\mathrm{s}} / Q_{\mathrm{o}}
$$

where $T_{\mathrm{t}}$ is transmissivity coefficient for the B-C model, $R_{\mathrm{s}}$ is daily solar radiation at the surface, and $Q_{\mathrm{o}}$ is daily solar radiation at the top of the atmosphere. $Q_{\mathrm{o}}$ is estimated by the equation presented in Goodin et al. (1999, Eq. [5], p. 846). $T_{\mathrm{t}}$ is estimated from $\mathrm{DR}(\Delta T)$ :

$$
\begin{aligned}
T_{\mathrm{t}} & =0.68\left[1-\exp \left(-0.03 \Delta T^{2.02}\right)\right] \\
\Delta T(d) & =T_{\max }(d)-\left[T_{\min }(d)+T_{\min }(d-1)\right] / 2
\end{aligned}
$$

where $T_{\max }$ and $T_{\min }$ are daily maximum and minimum air temperatures, respectively. The previous day's minimum air temperature is included in this equation to reduce the effect of large-scale advection of cold or warm air masses. The key aspect of the modified B-C method is inclusion of $Q_{0}$ as a scaling factor during calculation of $T_{\mathrm{t}}$. This modification can be expressed as follows (Goodin et al., 1999):

$$
T_{\mathrm{t}}=0.75\left\{1-\exp \left[-2.61\left(\Delta T^{0.76} / Q_{\mathrm{o}}\right)\right]\right\}
$$

Selection of the stations was primarily determined by the availability of solar radiation and air temperature data. Length of the time series for each variable was from 1990 through 1998. The reporting time for the daily observation was $2400 \mathrm{~h}$ (midnight) for these stations. However, as noted above, to identify the TOB, maximum and minimum air temperatures were defined from the hourly data for two assumed additional reporting times $(0800$ and $1600 \mathrm{~h})$. Subsequently, in addition to the two forms of B-C model, a regression-based M-H model was developed that used 27 sets of coefficients (nine stations $X$ three observation times). Each of these 27 sets of coefficients was developed based on data from respective stations (Fig. 1). A stepwise regression procedure is used for the model formulation. This approach develops a regression equation from a set of variables by including the most relevant subset of these variables. Initially, we have considered daily maximum and minimum air temperature, DR, and ICSKY as independent variables. The stepwise regression procedure demonstrated that DR and daily ICSKY would be sufficient for this study. Before the regression analysis, the data were logarithmically transformed because it was understood that the actual radiation would be well represented by scaling the clear-day solar radiation. Involving air temperature in the scaling process suggests a multiplicative relationship, and this nonlinearity was removed by transformation before the regression analysis. 
Table 1. The $\boldsymbol{r}^{2}$ between measured and predicted solar radiation for three observation times.

\begin{tabular}{|c|c|c|c|c|c|c|c|c|c|}
\hline \multirow[b]{2}{*}{ Station } & \multicolumn{3}{|c|}{0800 h } & \multicolumn{3}{|c|}{$1600 \mathrm{~h}$} & \multicolumn{3}{|c|}{$2400 \mathrm{~h}$} \\
\hline & $\mathbf{M}-\mathbf{H} \dagger$ & B-C $\div$ & M B-C§ & М-H & B-C & M B-C & M-H & B-C & M B-C \\
\hline Ord, NE & 0.44 & 0.46 & 0.30 & 0.55 & 0.62 & 0.48 & 0.66 & 0.73 & 0.57 \\
\hline Mead, NE & 0.45 & 0.46 & 0.45 & 0.56 & 0.61 & 0.61 & 0.65 & 0.71 & 0.71 \\
\hline Alliancewest, NE & 0.50 & 0.53 & 0.37 & 0.61 & 0.68 & 0.58 & 0.72 & 0.78 & 0.66 \\
\hline Parsons, KS & 0.46 & 0.46 & 0.29 & 0.60 & 0.62 & 0.46 & 0.66 & 0.82 & $\mathbf{0 . 5 3}$ \\
\hline Akron, CO & 0.50 & 0.54 & 0.39 & 0.62 & 0.71 & 0.62 & 0.75 & 0.82 & 0.70 \\
\hline Langdon, ND & 0.66 & 0.54 & 0.42 & 0.69 & 0.67 & 0.57 & 0.72 & 0.72 & 0.60 \\
\hline Williston, ND & 0.62 & 0.59 & 0.47 & 0.67 & 0.72 & 0.63 & 0.74 & 0.80 & 0.69 \\
\hline Watertown, ND & 0.53 & 0.49 & 0.35 & 0.59 & 0.63 & 0.53 & 0.65 & 0.71 & 0.57 \\
\hline Nisland, SD & 0.55 & 0.54 & 0.35 & 0.61 & 0.69 & 0.53 & 0.69 & 0.78 & 0.61 \\
\hline
\end{tabular}

$\dagger$ M-H, the Mahmood and Hubbard model proposed in this paper.

B-C, unmodified-recalibrated Bristow-Campbell model (Goodin et al., 1999; our Eq. [8] through [10]).

§ M B-C, modified Bristow-Campbell model (Goodin et al., 1999; Eq. [11]).

\section{RESULTS, MODEL SELECTION, AND EVALUATION}

The best agreement between observed and model (the $\mathrm{M}-\mathrm{H}$ and two forms of the $\mathrm{B}-\mathrm{C}$ )-predicted solar radiation was for $2400 \mathrm{~h}$, and the weakest agreement was for $0800 \mathrm{~h}$ (Table 1). An example from Akron, CO, shows that, compared with 0800-h observation time, the agreement between $\mathrm{M}-\mathrm{H}$ modeled and recorded solar radiation improved up to 24 and $50 \%$ for $1600-$ and 2400-h observation time, respectively. The unmodifiedrecalibrated $\mathrm{B}-\mathrm{C}$ model and the modified $\mathrm{B}-\mathrm{C}$ model show similar improvement with change of observation

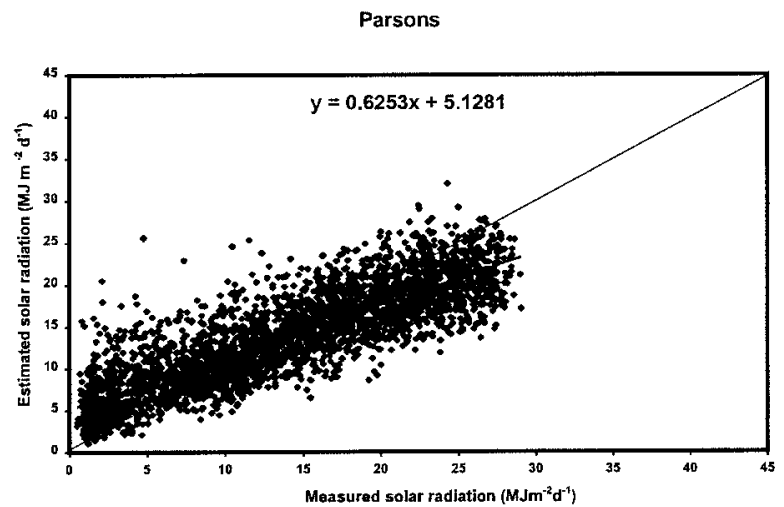

a.

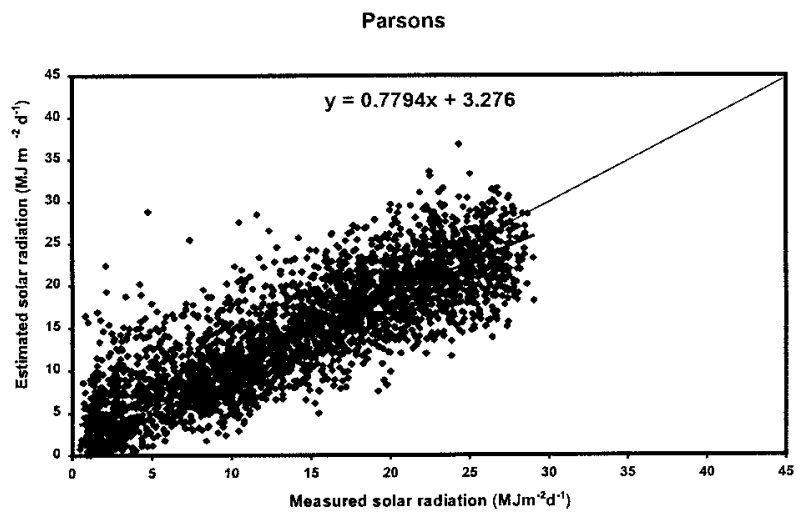

b.

Fig. 2. Scatterplot for measured and estimated solar radiation: (a) uncorrected for systematic error and (b) after correction. time. Thus, we use air temperature data with an observation time of $2400 \mathrm{~h}$. The performance of the model with these different sets of coefficients showed a regional trend. In most cases, all of the models for 2400-h observation time performed better at the drier western stations than at wetter eastern stations (Table 1). A Student's $t$-test was conducted and found that $r^{2}$ values for $2400 \mathrm{~h}$ were significantly higher than those from 0800 and $1600 \mathrm{~h}$ at $\alpha=0.005$.

Based on these findings, the M-H model adopted nine sets of site-specific coefficients formulated from 2400-h observations. The M-H model with each of these sets of parameters was applied to all nine stations (including point of origin) $(9 \times 9=81$ model runs $)$ for cross validation (Fig. 1) and to ascertain whether one model would perform satisfactorily for all nine stations representing the NGP. In addition, two forms of B-C models were applied to these sites for their performance evaluation.

The daily estimated and measured solar radiation were compared for the model evaluation. The model applications slightly overestimated lower values $(<5-7$ MJ $\mathrm{m}^{-2} \mathrm{~d}^{-1}$ ) and underestimated higher values (generally $>20 \mathrm{MJ} \mathrm{m}^{-2} \mathrm{~d}^{-1}$ ) (Fig. 2a). These biases are potentially associated with local-scale advection, frontal movement, and the regression method. Goodin et al. (1999) have also observed this type of bias. We proceeded to remove this systematic tendency to under- and overestimate at each site by a linear regression. Our analysis of model performance before and after the modification indicates that the modification to remove systematic bias improved performance of the model with all nine sets of coefficients (Fig. 2b). Tables 2 and 3 present results of the model performance. This study uses the root mean square error (RMSE) and $D$ index to evaluate the models (Willmott, 1981; Legates and McCabe, 1999). $D$ index can be expressed as follows:

$$
D=1.0-\left(\frac{\sum_{\mathrm{i}=1}^{\mathrm{N}}\left(O_{\mathrm{i}}-P_{\mathrm{i}}\right)^{2}}{\sum_{\mathrm{i}=1}^{\mathrm{N}}\left(\left|P_{\mathrm{i}}-\bar{O}\right|+\left|O_{\mathrm{i}}-\bar{O}\right|\right)^{2}}\right)
$$

where $O$ and $P$ are observed and predicted values, respectively.

Table 2 shows that RMSE did not improve after correction of systematic bias. On the other hand, the 
Table 2. Performance of solar radiation model after (before) removal of systematic bias and estimated by root mean square error. Model parameters are developed from the station data listed in the leftmost column.

\begin{tabular}{|c|c|c|c|c|c|c|c|c|c|}
\hline Stations & Ord, NE & Mead, NE & Alliancewest, NE & Parsons, KS & Akron, CO & Langdon, ND & Williston, ND & Watertown, SD & Nisland, SD \\
\hline \\
\hline Ord, NE & $5.05(4.38)$ & $4.89(4.30)$ & $5.91(5.83)$ & $4.52(4.42)$ & $4.87(4.08)$ & $5.81(5.34)$ & $5.25(5.09)$ & $5.40(5.11)$ & $5.59(5.32)$ \\
\hline Mead, NE & 5.18 (4.50) & $4.99(4.43)$ & 6.23 (3.95) & 4.58 (4.58) & 5.08 (4.25) & 5.77 (5.61) & $5.20(5.31)$ & 5.38 (5.35) & $5.66(5.53)$ \\
\hline Alliancewest, NE & 4.48 (4.44) & 4.39 (4.38) & 4.14 (3.65) & $4.40(4.54)$ & 4.18 (4.32) & $5.74(5.35)$ & $5.35(5.24)$ & $5.38(5.15)$ & $5.49(5.45)$ \\
\hline Parsons, KS & 5.84 (4.45) & 5.59 (4.35) & 7.48 (4.47) & 4.99 (4.35) & $6.18(4.16)$ & $6.09(5.36)$ & 5.58 (4.97) & $5.70(5.09)$ & $6.18(5.26)$ \\
\hline Akron, CO & $4.52(4.25)$ & 4.39 (4.18) & $4.91(3.92)$ & $4.18(4.20)$ & 3.90 (3.61) & 4.93 (4.67) & $4.47(4.43)$ & $4.68(4.54)$ & $4.86(4.77)$ \\
\hline Langdon, ND & $5.69(4.34)$ & $5.65(4.32)$ & $6.29(3.87)$ & $5.52(4.34)$ & $4.78(3.62)$ & 4.50 (4.11) & 4.29 (4.11) & $4.82(4.25)$ & $4.71(4.39)$ \\
\hline Williston, ND & $5.58(4.46)$ & $5.45(4.40)$ & $6.61(4.48)$ & $5.13(4.32)$ & $4.95(3.49)$ & 4.49 (4.08) & $4.20(3.87)$ & $4.60(4.16)$ & $4.86(4.30)$ \\
\hline Watertown, SD & $5.78(4.26)$ & $5.62(4.21)$ & $6.99(4.03)$ & 5.21 (4.18) & $5.35(3.46)$ & 4.92 (4.26) & 4.58 (4.09) & $4.89(4.25)$ & $5.18(4.43)$ \\
\hline Nisland, SD & 5.33 (4.26) & $5.22(4.22)$ & 6.19 (4.01) & $4.94(4.20)$ & $4.74(3.49)$ & 4.72 (4.17) & $4.40(4.04)$ & 4.73 (4.21) & 4.82 (4.35) \\
\hline
\end{tabular}

Table 3. Performance of solar radiation model after (before) removal of systematic bias and as estimated by $D$ index. Model parameters are developed from the station data listed in the leftmost column.

\begin{tabular}{|c|c|c|c|c|c|c|c|c|c|}
\hline Stations & Ord, NE & Mead, NE & Alliancewest, $\mathbf{N E}$ & Parsons, KS & Akron, CO & Langdon, ND & Williston, ND & Watertown, SD & Nisland, SD \\
\hline Ord, NE & $0.90(0.90)$ & $0.91(0.90)$ & $0.88(0.93)$ & $0.91(0.88)$ & $0.92(0.97)$ & 0.88 (0.86) & $0.91(0.89)$ & $0.88(0.86)$ & $0.90(0.87)$ \\
\hline Mead, NE & $0.90(0.90)$ & $0.91(0.90)$ & $0.88(0.92)$ & $0.91(0.88)$ & $0.92(0.92)$ & $0.88(0.85)$ & $0.91(0.88)$ & $0.88(0.85)$ & $0.90(0.87)$ \\
\hline Alliancewest, NE & $0.91(0.89)$ & $0.91(0.89)$ & $0.92(0.93)$ & $0.89(0.87)$ & $0.93(0.93)$ & $0.86(0.86)$ & $0.89(0.87)$ & $0.86(0.84)$ & $0.88(0.86)$ \\
\hline Parsons, KS & $0.89(0.91)$ & $0.89(0.91)$ & $0.85(0.92)$ & $0.90(0.90)$ & $0.89(0.93)$ & $0.88(0.87)$ & $0.91(0.90)$ & $0.88(0.87)$ & $0.89(0.89)$ \\
\hline Akron, CO & $0.91(0.90)$ & $0.91(0.90)$ & $0.90(0.92)$ & $0.91(0.89)$ & $0.94(0.93)$ & $0.90(0.89)$ & $0.92(0.91)$ & $0.90(0.88)$ & $0.91(0.89)$ \\
\hline Langdon, ND & $0.88(0.89)$ & $0.88(0.90)$ & $0.86(0.92)$ & $0.87(0.88)$ & $0.92(0.93)$ & $0.92(0.91)$ & $0.94(0.92)$ & $0.91(0.90)$ & $0.92(0.91)$ \\
\hline Williston, ND & $0.88(0.90)$ & $0.89(0.90)$ & $0.85(0.90)$ & $0.88(0.89)$ & $0.91(0.94)$ & $0.92(0.92)$ & $0.94(0.93)$ & $0.91(0.91)$ & $0.92(0.92)$ \\
\hline Watertown, SD & $0.88(0.90)$ & $0.89(0.90)$ & $0.85(0.92)$ & $0.89(0.89)$ & $0.91(0.94)$ & $0.91(0.91)$ & $0.93(0.92)$ & $0.91(0.90)$ & $0.92(0.91)$ \\
\hline Nisland, SD & $0.89(0.90)$ & $0.90(0.90)$ & $0.87(0.92)$ & $0.89(0.89)$ & $0.92(0.94)$ & 0.92 (0.91) & $0.94(0.93)$ & $0.91(0.90)$ & 0.92 (0.91) \\
\hline
\end{tabular}

$D$ index largely indicated improvement in model performance after introducing correction for systematic bias (Table 3). It was found that 39 cases, out of 81 (48\%), demonstrate improvement (Table 3). Note that after correction, the $D$ index remained unchanged for 13 additional cases (Table 3). Moreover, according to the $D$ index, the M-H model estimates based on Akron, CO, data were an improvement in most cases (eight out of nine applications). We conclude that correction for systematic error improved the scatter of data points around the 1:1 line (Fig. 2a and 2b). This is also demonstrated by improvement in slope and intercept estimates (Fig. $2 \mathrm{a}$ and $2 \mathrm{~b}$ ).

The RMSE statistic indicates that in most cases, model performance showed certain regional bias (Table 2). Models that used coefficients developed from relatively sunny or cloudy sites performed better for similar sites. For example, the Williston, ND, coefficient-based M-H model performed better for other northern, less cloudy sites (Fig. 3a and 3b) while the Ord, NE, coefficientbased model performed better (Fig. 4a and 4b) for other southeastern, more cloudy sites (Table 2). The $D$ index showed similar regional patterns (Table 3 ). In other words, this regional pattern of performance by the model and site-specific coefficients appears to be related to the climate they represent. Further examination indicated that one model gave good performance over the whole NGP. The coefficients derived from Akron, CO, data were the only form of the model for which the $D$ index was consistently higher than 0.90 for all sites. For five sites, the Akron, CO, coefficient-based M-H model produced the highest $D$ statistics, and for two applications, it produced the second highest $D$ statistics. In addition, the Akron, $\mathrm{CO}$, coefficient-based model was the only model producing RMSE values lower than $5 \mathrm{MJ} \mathrm{m}^{-2} \mathrm{~d}^{-1}$ for all sites. This model produced the three lowest and three second-lowest RMSE estimates. Also, the Akron, CO, coefficient-based model estimated

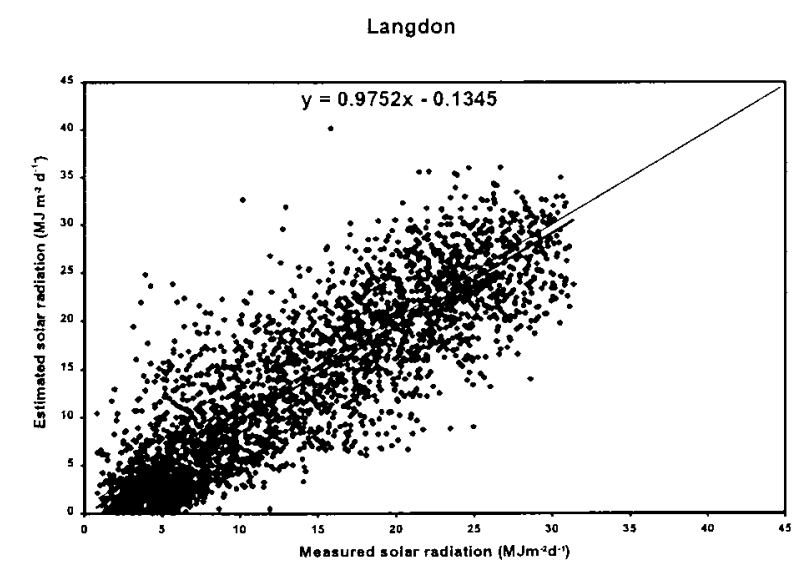

a.

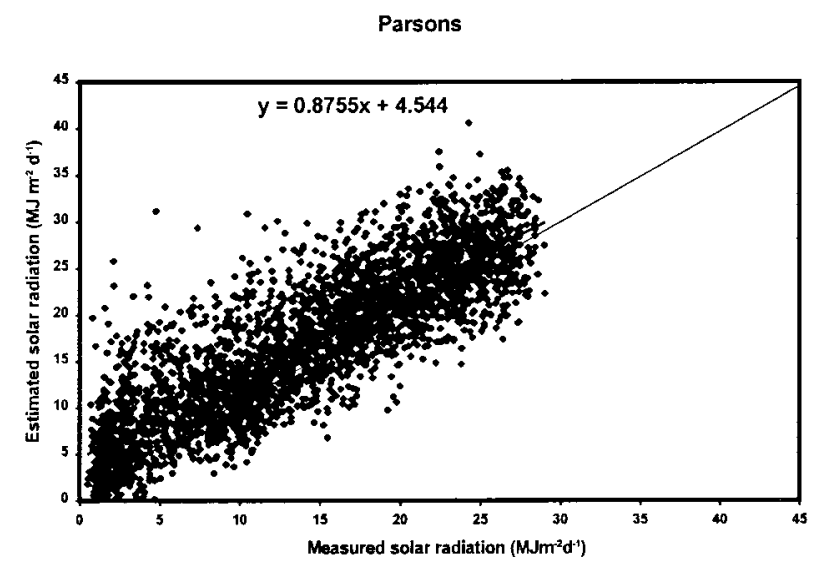

b.

Fig. 3. Application of the Williston, ND, model and resultant scatterplot of measured and estimated solar radiation for (a) Langdon, ND, and (b) Parsons, KS. 


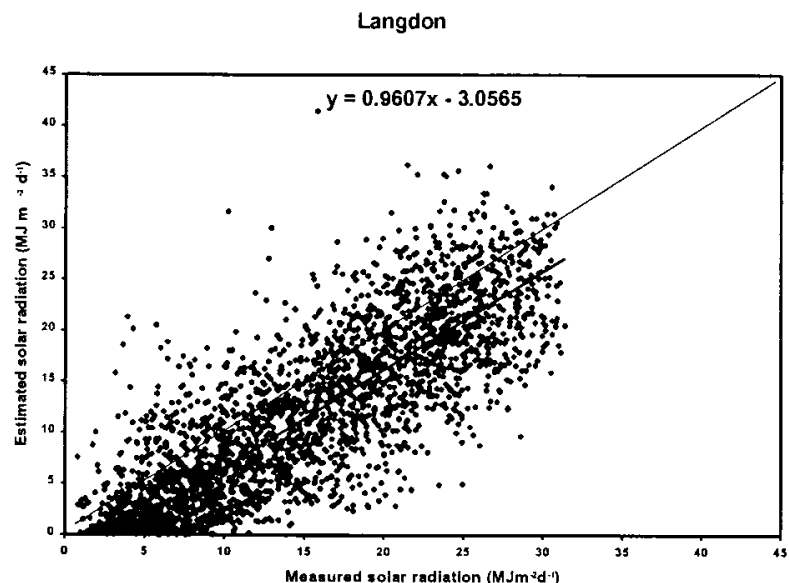

a.

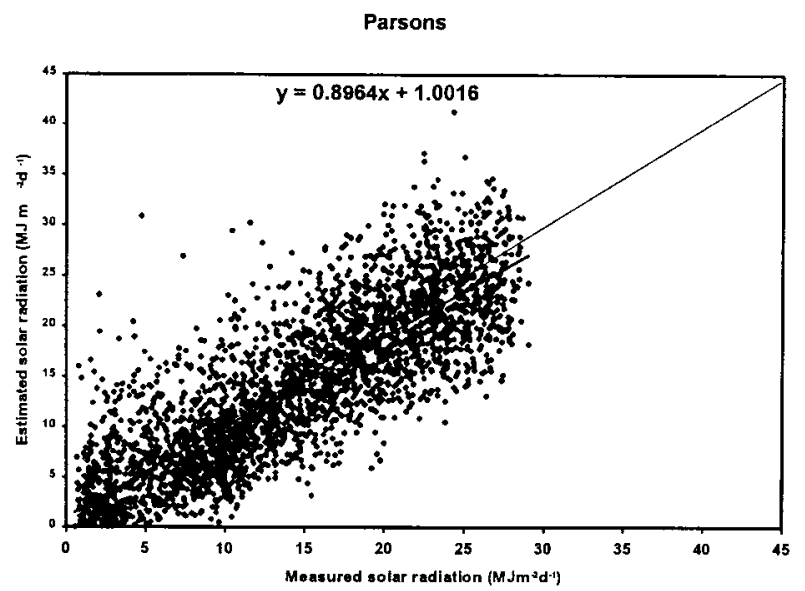

b.

Fig. 4. Application of the Ord, NE, model and resultant scatterplot of measured and estimated solar radiation for (a) Langdon, ND, and (b) Parsons, NE.

the lowest and second-lowest relative error [RMSE/ mean (\%)] for five and three sites, respectively (Table 4). Furthermore, compared with the model with the other eight sets of coefficients, scatter plots for Akron, $\mathrm{CO}$, coefficient-based $\mathrm{M}-\mathrm{H}$ model showed a relatively satisfactory distribution of estimated solar radiation values about the 1:1 line (Fig. 5a and 5b). As a result, we
Ord

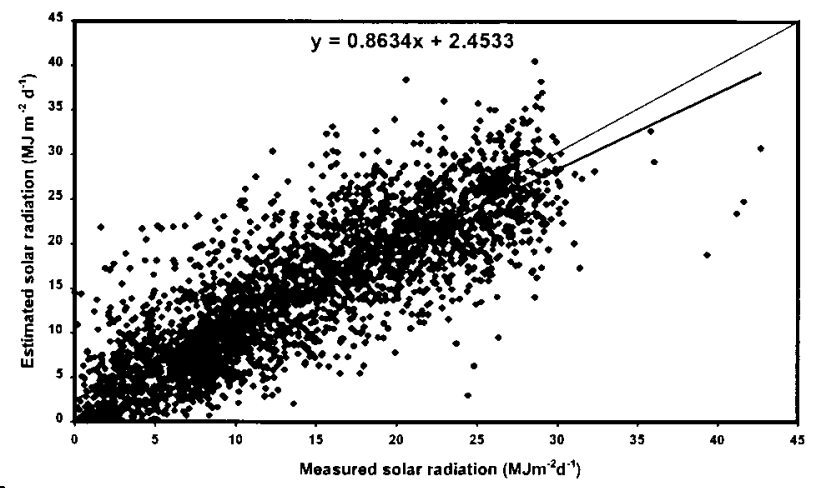

a.

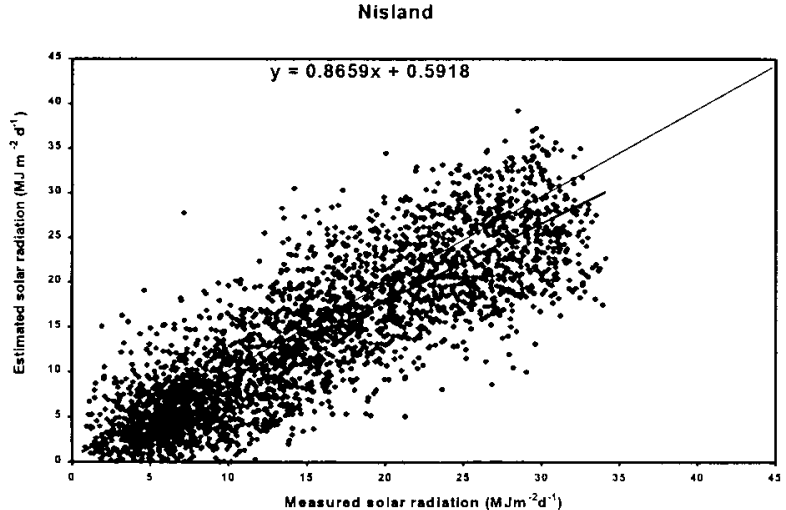

b.

Fig. 5. Application of the Akron, CO, model (Eq. [7] and [8]) and resultant scatterplot of measured and estimated solar radiation for (a) Ord, NE, and (b) Nisland, SD. Body Text

have selected the model with coefficients derived and adopted from Akron, CO, data. This model can be expressed as follows:

$$
\begin{aligned}
Y & =0.182 \times \mathrm{DR}^{0.69} \times \mathrm{ICSKY}^{0.91} \\
Y_{\text {mod }} & =(Y-2.4999) / 0.8023
\end{aligned}
$$

where $Y$ is estimated solar radiation $\left(\mathrm{MJ} \mathrm{m}^{-2} \mathrm{~d}^{-1}\right)$ uncorrected for systematic bias and $Y_{\bmod }$ is estimated solar radiation $\left(\mathrm{MJ} \mathrm{m}^{-2} \mathrm{~d}^{-1}\right)$ corrected for bias. Equation [14] reduces systematic bias in estimated solar radiation. It acts as a mechanism for algebraic manipulation of an

Table 4. Performance of solar radiation model based on relative error [(RMSE $\dagger / m e a n) \times 100]$ estimates. Model parameters are developed from the station data listed in the leftmost column. (Number of observations $=3287$ per site.)

\begin{tabular}{|c|c|c|c|c|c|c|c|c|c|}
\hline Ord, NE & 36 & 36 & 40 & 31 & 28 & 43 & 36 & 40 & 36 \\
\hline Mead, NE & 37 & 36 & 42 & 32 & 29 & 43 & 36 & 39 & 36 \\
\hline Alliancewest, NE & 32 & 32 & 28 & 31 & 24 & 43 & 37 & 39 & 35 \\
\hline Parsons, KS & 41 & 41 & 51 & 35 & 36 & 45 & 39 & 42 & 40 \\
\hline Akron, CO & 32 & 32 & 33 & 24 & 22 & 37 & 31 & 34 & 31 \\
\hline Langdon, ND & 40 & 41 & 43 & 39 & 27 & 33 & 30 & 35 & 30 \\
\hline Williston, ND & 39 & 40 & 45 & 36 & 28 & 33 & 29 & 34 & 31 \\
\hline Watertown, SD & 41 & 41 & 47 & 36 & 31 & 37 & 32 & 36 & 33 \\
\hline Nisland, SD & 38 & 38 & 42 & 34 & 27 & 35 & 30 & 35 & 31 \\
\hline
\end{tabular}

Stations Ord, NE Mead, NE Alliancewest, NE Parsons, KS Akron, CO Langdon, ND Williston, ND Watertown, SD Nisland, SD

$\dagger$ RMSE, root mean square error. 
Table 5. Accuracy of seasonal solar radiation estimates for Parsons, KS, and Williston, ND. The estimates are based on Eq. [7] and [8].

\begin{tabular}{|c|c|c|c|c|c|c|}
\hline & \multicolumn{2}{|c|}{ RMSE $\dagger$} & \multicolumn{2}{|c|}{ Mean } & \multicolumn{2}{|c|}{ Error } \\
\hline & Parsons & Williston & Parsons & Williston & Parsons & Williston \\
\hline & & $-\mathbf{N}$ & 1 & - & 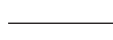 & - \\
\hline \multirow{2}{*}{$\begin{array}{l}\text { Summer DOY } \$ \text { : 121-273 } \\
\text { Winter DOY: 1-120 and 274-365 }\end{array}$} & 4.49 & 4.01 & 19.38 & 21.17 & 23 & 19 \\
\hline & 3.94 & 5.05 & 10.35 & 9.33 & 38 & 54 \\
\hline
\end{tabular}

$\dagger$ RMSE, root mean square error.

+ DOY, day of year.

established relationship demonstrated in Eq. [14]. The calculation and quality control procedures of ICSKY and DR, respectively, minimized the possibility of large errors in the independent variables. The ICSKY is estimated based on well-known relationships among clearsky solar radiation, latitude, and DOY. Note that the coefficient for DR ranged from 0.04 to 0.32 , its exponent coefficient ranged from 0.44 to 0.86 , and exponent coefficient for ICSKY ranged from 0.91 to 1.21 for the nine sites. The Automated Weather Data Network of the NGP is a well-maintained mesoscale network, which assures high quality data for a number of meteorological variables, including maximum and minimum air temperature. Therefore, the possibility of large errors in the independent variables is reduced and the validity of the model upheld. Also, the model evaluation statistics demonstrate its reliability and suggest minimum errors in the independent variables.

It is important to note that the satisfactory performance of this model (Eq. [13] and [14]) for sites scattered over such a large region with significant latitudinal extent and climatic dissimilarity is a key reason to select this model for solar radiation estimation in the NGP. For example, latitudinal difference between Parsons, KS, and Williston, ND, is nearly $11^{\circ}$. Moreover, Parsons, $\mathrm{KS}$, is relatively warmer and cloudier compared with Williston, ND. Ranges of average January and July air temperatures for Williston, ND, and its neighboring regions are -15 to $-12^{\circ} \mathrm{C}$ and 20 to $22^{\circ} \mathrm{C}$, respectively, while for Parsons, KS, the same measures are -6 to $-4^{\circ} \mathrm{C}$ and 24 to $27^{\circ} \mathrm{C}$, respectively. In addition, unlike other $\mathrm{M}-\mathrm{H}$ models in this study, the Akron, $\mathrm{CO}$, coefficient-based model (Eq. [13] and [14]) does not show a regional bias during its applications to other sites. Akron, $\mathrm{CO}$, is a relatively less cloudy site, like the other northern sites, while thermally, it ranks between the northern and southern locations. These climatic characteristics may be the reasons that the coefficients from Akron, CO, best suit both northern and southern sites and provide satisfactory estimates of daily solar radiation for the entire NGP.

It is possible to speculate that the M-H model would estimate solar radiation satisfactorily under many other climatic conditions. The performance of this model under a wide variety of conditions led us to suggest the above. Although the study region is the NGP, the climatic conditions observed within this region are representative of many other regions of the world. As noted above, these include, for example, conditions ranging from the subhumid to semiarid and extreme to moderately cold winter conditions. Thus, the $\mathrm{M}-\mathrm{H}$ model is sufficiently robust for application in other regions of the world.
However, a recalibration of the $\mathrm{M}-\mathrm{H}$ model with local data would potentially provide more suitable coefficients and subsequently, more accurate estimation of solar radiation. The performance of the $\mathrm{M}-\mathrm{H}$ model in the coastal areas, areas under maritime climate, or at higher elevation remains to be seen.

Table 5 demonstrates the accuracy of the model estimates during summer and winter (cf., Bristow and Campbell, 1984; Goodin et al., 1999) for Parsons, KS, and Williston, ND. The table showed, based on RMSE, that estimates for Parsons (Williston) during the winter (summer) season were relatively more accurate compared with the summer (winter) season (see Fig. 6a, 6b,

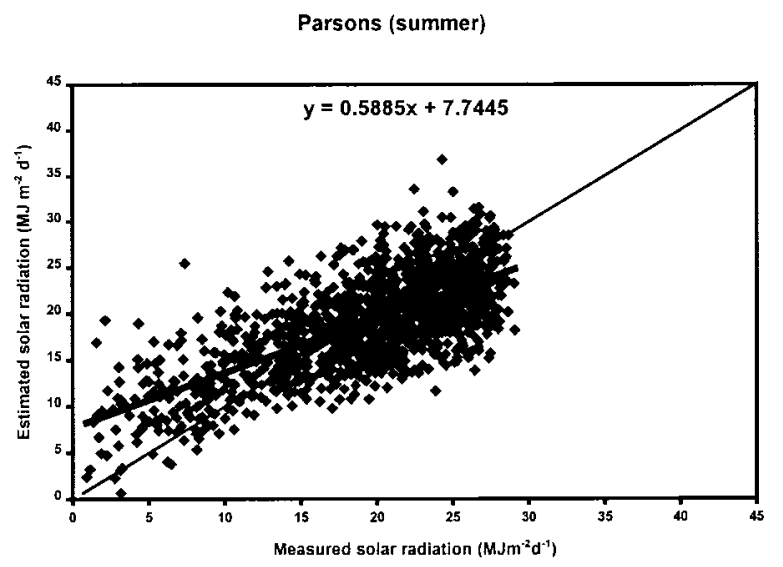

a.

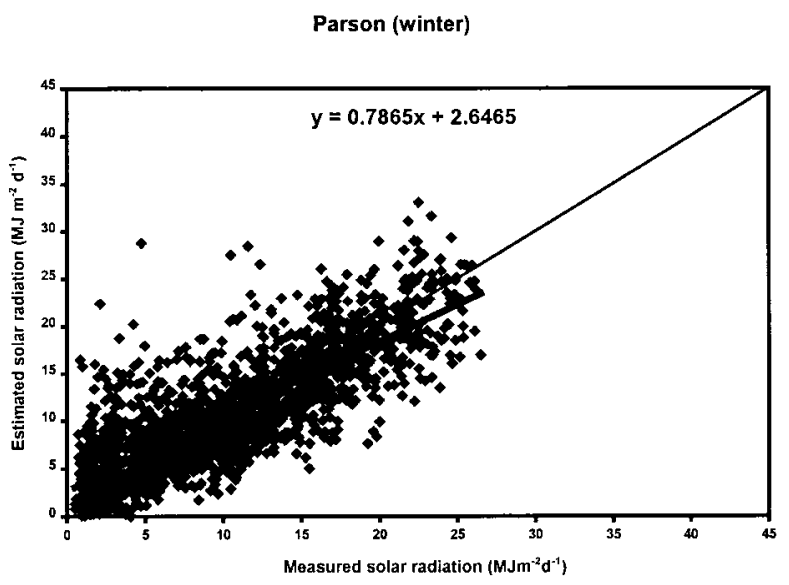

b.

Fig. 6. Application of the Akron, CO, model and resultant scatterplot of measured and estimated solar radiation for Parsons, KS: (a) high sun and (b) low sun. 


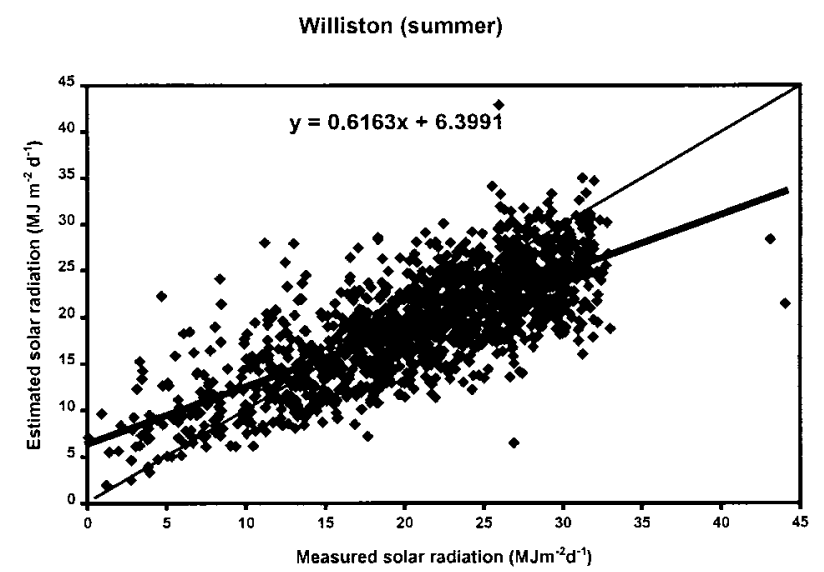

a.

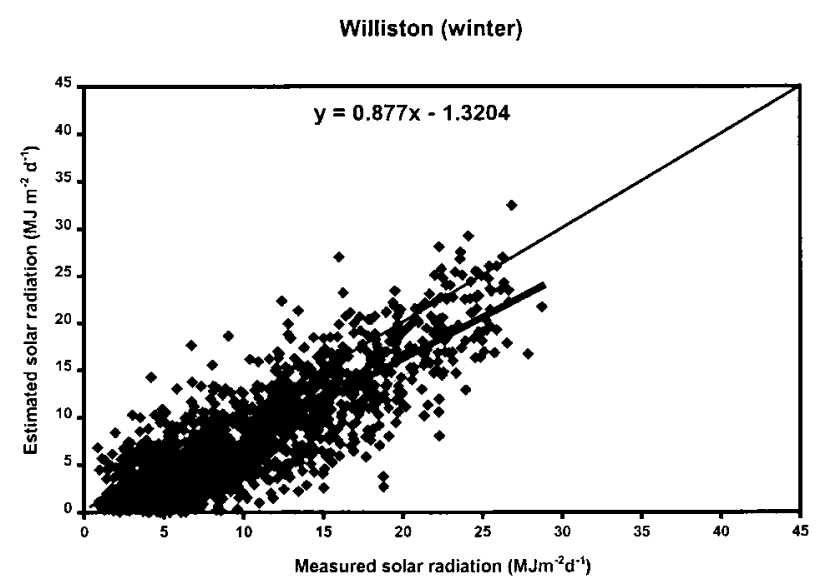

b.

Fig. 7. Application of the Akron, CO, model and resultant scatterplot of measured and estimated solar radiation for Williston, ND: (a) summer and (b) winter.

7a, and 7b). However, error analysis shows that the model estimates for both of these sites is better during the summer season. Overall, the results indicate that both season and location influenced the model estimates. To further determine the performance of this model, two indices were developed. They are, namely, QRATIO and EQRATIO. These two indices can be expressed as follows:

$$
\begin{aligned}
\text { QRATIO } & =\left(\overline{R_{0}}\right) /(\overline{\text { ICSKY }}) ; \text { and } \\
\text { EQRATIO } & =\left(\overline{Y_{\text {mod }}}\right) /(\overline{\text { ICSKY }})
\end{aligned}
$$

where $\overline{R_{0}}$ is measured mean daily solar radiation, $\overline{\mathrm{ICSKY}}$ is mean daily corrected clear-sky radiation, and $\overline{Y_{\bmod }}$ is estimated mean daily solar radiation. Thus, QRATIO indicates the cloudiness of a site, and the difference between QRATIO and EQRATIO indicates mean bias in the radiation estimates. The difference is expressed as percentage.

$$
\text { Mean bias }=\mid \text { QRATIO }- \text { EQRATIO } \mid \times 100
$$

Table 6. Mean error estimates for the model-based solar radiation calculation.

\begin{tabular}{lr}
\hline Stations & Error \\
\hline & $\%$ \\
Ord, NE & 3 \\
Mead, NE & 2 \\
Alliancewest, NE & 11 \\
Parsons, KS & 0 \\
Akron, CO & 0 \\
Langdon, ND & 16 \\
Williston, ND & 14 \\
Watertown, SD & 11 \\
Nisland, SD & 9 \\
\hline
\end{tabular}

Table 6 presents the mean error of daily solar radiation estimates. The errors range between 0 to $16 \%$ for all of the sites.

Like some other models for NGP (cf., Goodin et al., 1999), the M-H model has a tendency to underestimate higher values, even after modification. This limitation of the $\mathrm{M}-\mathrm{H}$ model is potentially related to, as noted above, local heat advection and passage of fronts. During cross validation and model selection, we have found that, for some sites, the selected model (Eq. [13] and [14]) performs better than the models that were developed with the data recorded at the sites. For example, the Akron, CO, coefficient-based M-H model (Eq. [13] and [14]) performs better for Ord, NE, than does the Ord, NE, coefficient-based M-H model (Table 3). Similar performances were observed for the $\mathrm{M}-\mathrm{H}$ model with other site-specific coefficients too (Table 3).

The forcing factors that were not included may have a role in this type of model performance. For example, elevation, dust storms, seasonal burning, grassland fires, and pollution from fires may significantly influence measured radiation (e.g., Thornton and Running, 1999). Thornton and Running (1999) noted that underlying surface conditions can potentially introduce bias in the estimates. In addition, various other atmospheric constituents such as $\mathrm{O}_{2}, \mathrm{CO}_{2}, \mathrm{O}_{3}, \mathrm{CH}_{4}$, and anthropogenic gases also influence the amount of incident radiation (Rosenberg et al., 1983; Oke, 1987), and thus affect the performance this type of model. A sensitivity analysis of the present model showed that estimated solar radiation increases linearly with increasing DR (Fig. 8). Generally, sensitivity of $Y_{\bmod }$ to DR was higher (lower) for higher (lower) ICSKY. Under extremely high DR (e.g., $20^{\circ} \mathrm{C}$ ) and high ICSKY, this model is capable of estimating $\mathrm{Y}_{\text {mod }}$ higher than ICSKY. On the other hand, when $\mathrm{DR} \leq 15^{\circ} \mathrm{C}$, the model estimates of $\mathrm{Y}_{\bmod }$ were lower than those of ICSKY. The estimates were significantly lower when $\mathrm{DR} \leq 10^{\circ} \mathrm{C}$. These responses partially explain under- and overestimation by the model. Moreover, results from the sensitivity analysis indicated that inclusion of previously mentioned environmental forcing factors (e.g., local advection and frontal passage) in the model might have explained some of the biases.

The selection of the M-H model (Eq. [13] and [14]) prepared us for its further performance evaluation and comparison to the unmodified-recalibrated and modified B-C model proposed by Goodin et al. (1999). Obviously, based on the above findings regarding impacts of TOB, model evaluation statistics for these two forms of 


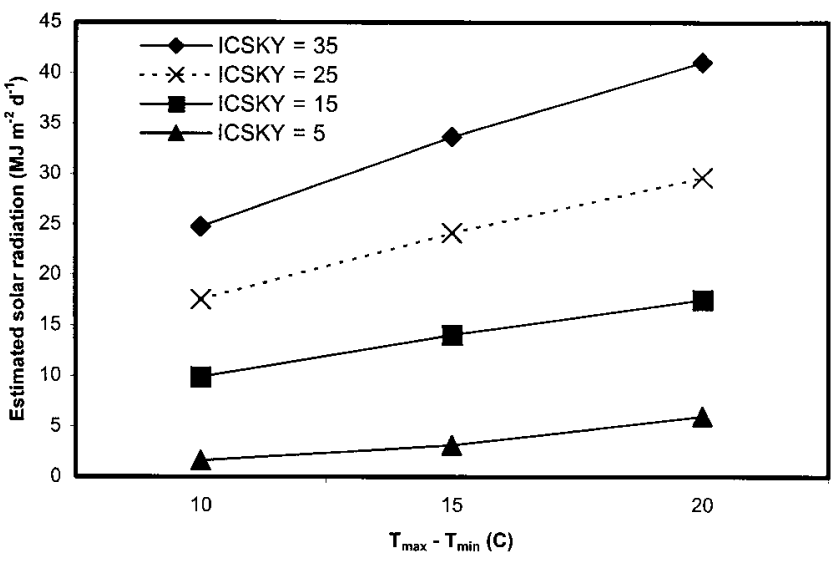

Fig. 8. Sensitivity analysis of estimated solar radiation under various maximum and minimum air temperature ranges. ICSKY, corrected clear-sky solar radiation $\left(\mathrm{MJ} \mathrm{m}^{-2} \mathrm{~d}^{-1}\right)$.

the B-C model are calculated using 2400-h observation time. A comparison of these statistics shows that the unmodified-recalibrated B-C model is slightly superior to the $\mathrm{M}-\mathrm{H}$ model. Table 7 shows that RMSE of the unmodified-recalibrated B-C model (Eq. [8] and [9]) is lower at seven sites while $D$ index is higher at six sites compared with the M-H (Eq. [13] and [14]) model. The ranges of RMSE, $D$ index, and relative error for the unmodified-recalibrated B-C model are 3.53 to 4.78 MJ m ${ }^{-2} \mathrm{~d}^{-1}, 0.94$ to 0.91 , and 20 to $36 \%$, respectively. The same measures for the $\mathrm{M}-\mathrm{H}$ model are 3.90 to 4.93 MJ m ${ }^{-2} \mathrm{~d}^{-1}, 0.94$ to 0.90 , and 22 to $37 \%$, respectively. On the other hand, the modified B-C model (Eq. [8] and [11]) consistently performed quite unsatisfactorily compared with these two models. The range of RMSE, $D$ index, and relative errors are 7.06 to $9.16 \mathrm{MJ} \mathrm{m}^{-2}$ $\mathrm{d}^{-1}, 0.67$ to 0.56 , and 45 to $62 \%$, respectively. It is also found that the unmodified-recalibrated B-C model underestimates high solar radiation values, like the $\mathrm{M}-\mathrm{H}$ model (Fig. 9). Goodin et al. (1999), from their Kansas applications, have shown that the modified B-C was superior to the unmodified-recalibrated B-C model. Thus, the modified B-C model (Eq. [11]) did not perform better than the unmodified-recalibrated B-C model for a larger region. We can only assume that the empirical nature of all methods plays a role in these results. For this study, the $\mathrm{M}-\mathrm{H}$ model $\left(\mathrm{RMSE}=4.18 \mathrm{MJ} \mathrm{m}^{-2} \mathrm{~d}^{-1}\right)$ and the unmodified-recalibrated B-C model (RMSE $=$
Akron

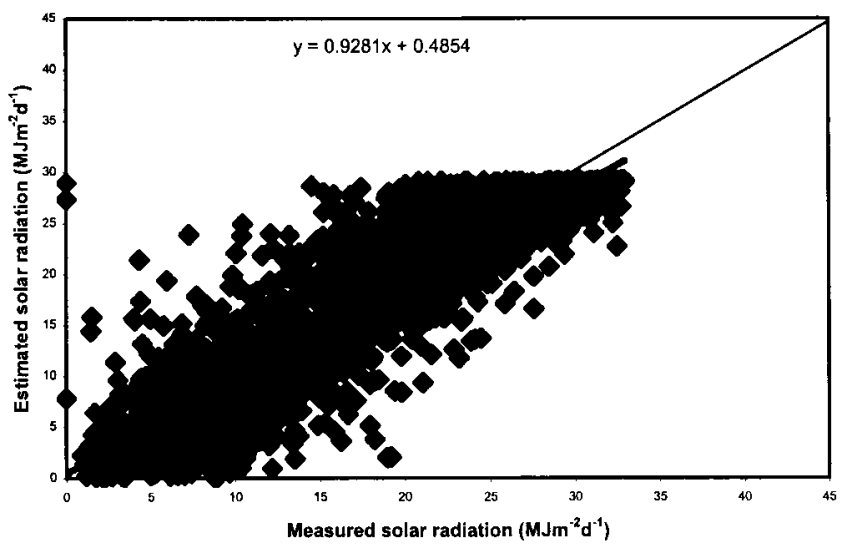

Fig. 9. Application of the unmodified-recalibrated B-C model to Akron, CO.

4.27 $\left.\mathrm{MJ} \mathrm{m}^{-2} \mathrm{~d}^{-1}\right)$ performed superior to the modified B-C model ( $\mathrm{RMSE}=8.02 \mathrm{MJ} \mathrm{m}^{-2} \mathrm{~d}^{-1}$ ) at Parsons, KS. Goodin et al. (1999) reported a RMSE of $4.68 \mathrm{MJ} \mathrm{m}^{-2}$ $\mathrm{d}^{-1}$ for the application of the modified B-C model at Parsons, KS. These contrasting results from the two applications of the modified B-C model at the same site only can be attributed to the data sets used in these two studies. Overall, it is quite clear that the $\mathrm{M}-\mathrm{H}$ model and the unmodified-recalibrated B-C model (also Goodin et al., 1999) performed better compared with the modified B-C model during their applications for a larger region (i.e., the NGP).

Additionally, Goodin et al. (1999) argued that latitudinal deviation of Parsons from Manhattan influenced the performance of the modified B-C model at Parsons. The latitudinal and longitudinal difference between Akron, CO, and Parsons and between Williston, ND, and Parsons is much greater. Considering these deviations, the performances of the unmodified-recalibrated B-C (Goodin et al., 1999) and Akron, CO, coefficientbased model (the $\mathrm{M}-\mathrm{H}$ ) are superior compared with the modified B-C model. Goodin et al. (1999) evaluated the performance of the recalibrated and the reformulated B-C methods. Interestingly, they have reported RMSE of 5.81 and $5.20 \mathrm{MJ} \mathrm{m}^{-2} \mathrm{~d}^{-1}$, respectively, for Manhattan, $\mathrm{KS}$, applications. The $\mathrm{M}-\mathrm{H}$ model in this paper was applied to Akron, CO, and an RMSE of $3.90 \mathrm{MJ} \mathrm{m}^{-2} \mathrm{~d}^{-1}$

Table 7. Comparison of the three model performances for nine sites based on root mean square error (RMSE), $D$ index, and relative error [(RMSE/mean) $\times 100]$.

\begin{tabular}{|c|c|c|c|c|c|c|c|c|c|}
\hline Model & Ord, NE & Mead, NE & Alliancewest, NE & Parsons, KS & Akron, CO & Langdon, ND & Williston, ND & Watertown, SD & Nisland, SD \\
\hline M-H & & 4.39 & 4.91 & 4.18 & 3.90 & 4.93 & 4.47 & 4.68 & 4.86 \\
\hline $\begin{array}{l}\text { RMSE, MJ } \mathrm{m}^{-2} \mathrm{~d}^{-1} \\
D \text { index } \\
\text { Relative error, } \%\end{array}$ & $\begin{array}{l}4.52 \\
0.91 \\
32\end{array}$ & 32 & $\mathbf{3 3}^{\mathbf{0 . 9 0}}$ & $2^{0.91}$ & $2^{0.94}$ & $\begin{array}{l}\mathbf{0 . 9 0} \\
37\end{array}$ & 31 & $\begin{array}{l}0.90 \\
34\end{array}$ & 31 \\
\hline \multicolumn{10}{|c|}{ Unmodified-recalibrated B-C } \\
\hline $\begin{array}{l}\text { RMSE, MJ } \mathbf{~ m}^{-2} \mathbf{d}^{-1} \\
D \text { index } \\
\text { Relative error, } \%\end{array}$ & $\begin{array}{l}4.32 \\
0.92 \\
30\end{array}$ & $\begin{array}{l}4.53 \\
0.91 \\
33\end{array}$ & $\begin{array}{c}4.03 \\
0.93 \\
27\end{array}$ & $\begin{array}{l}4.27 \\
0.91 \\
25\end{array}$ & $\begin{array}{l}3.53 \\
0.94 \\
20\end{array}$ & $\begin{array}{l}4.78 \\
0.91 \\
36\end{array}$ & $\begin{array}{l}4.14 \\
0.94 \\
29\end{array}$ & $\begin{array}{l}4.58 \\
0.91 \\
33\end{array}$ & $\begin{array}{l}4.25 \\
0.93 \\
27\end{array}$ \\
\hline \multicolumn{10}{|l|}{ Modified B-C } \\
\hline $\begin{array}{l}\overline{\text { RMSE, MJ m }} \\
D \text { index } \\
\text { Relative error, } \%\end{array}$ & $\begin{array}{l}7.76 \\
0.64 \\
55\end{array}$ & $\begin{array}{c}7.68 \\
0.68 \\
56\end{array}$ & $\begin{array}{l}7.06 \\
0.67 \\
48\end{array}$ & $\begin{array}{l}8.02 \\
0.60 \\
47\end{array}$ & $\begin{array}{l}9.07 \\
0.63 \\
45\end{array}$ & $\begin{array}{c}8.29 \\
0.62 \\
62\end{array}$ & $\begin{array}{r}8.71 \\
0.63 \\
61\end{array}$ & $\begin{array}{r}8.19 \\
0.56 \\
61\end{array}$ & $\begin{array}{c}9.16 \\
0.58 \\
59\end{array}$ \\
\hline
\end{tabular}


was calculated. Therefore, it is apparent that if we apply these models to their sites of origin, the $\mathrm{M}-\mathrm{H}$ model provides relatively better estimates.

The coefficients for the unmodified-recalibrated B-C were derived from Manhattan, KS, data, and the model performed quite satisfactorily for these nine sites located over a large region. Nonetheless, like the M-H (Eq. [13] and [14]) model, the unmodified-recalibrated B-C (Eq. [8] and [9]) shows regional bias. The accuracy of the unmodified-recalibrated B-C estimates is better for all four drier western sites, as demonstrated by the four lower RMSE and $D$ index estimates (Table 7). Performance evaluation of the unmodified-recalibrated B-C model for the four western sites resulted in, on the average, RMSE and $D$ index of $3.98 \mathrm{MJ} \mathrm{m}^{-2} \mathrm{~d}^{-1}$ and 0.93 , respectively. Meanwhile, evaluation of the M-H model performance for four western sites resulted in an average RMSE and $D$ index of $4.45 \mathrm{MJ} \mathrm{m}^{-2} \mathrm{~d}^{-1}$ and 0.91 , respectively. A RMSE and $D$ index of $4.49 \mathrm{MJ} \mathrm{m}^{-2} \mathrm{~d}^{-1}$ and 0.91 , respectively, are obtained from application of the unmodified-recalibrated B-C model to five eastern sites. Average RMSE and $D$ index of 4.54 and 0.90, respectively, are derived for five eastern sites from the $\mathrm{M}-\mathrm{H}$ model evaluation. The difference of average RMSE and $D$ index between the unmodified-recalibrated B-C and the $\mathrm{M}-\mathrm{H}$ model is greater $\left(0.47 \mathrm{MJ} \mathrm{m}^{-2} \mathrm{~d}^{-1}\right.$ and 0.02 , respectively) for western region compared with eastern region (0.06 $\mathrm{MJ} \mathrm{m}^{-2} \mathrm{~d}^{-1}$ and 0.01 , respectively) of the NGP. Despite overall slightly improved performance of the unmodified-recalibrated B-C model for the NGP, the $\mathrm{M}-\mathrm{H}$ model shows more consistent sensitivity during its applications to western and eastern sites. The difference between average RMSE and $D$ index for the M-H model's applications to western and eastern sites of the NGP are $0.09 \mathrm{MJ} \mathrm{m}^{-2} \mathrm{~d}^{-1}$ and 0.01 , respectively. Similarly, the difference between the unmodified-recalibrated B-C model's evaluation estimates for western and eastern sites is $0.51 \mathrm{MJ} \mathrm{m}^{-2} \mathrm{~d}^{-1}$ and 0.02 , respectively.

It is necessary to emphasize that the M-H (Eq. [13] and [14]) model is not developed to validate or disqualify the B-C method. Instead, it focuses on the formulation of a method that follows a similar underlying principle as that of the B-C method and which is applicable to a large area of the NGP with varied environmental conditions. However, details of the formulation are different from the B-C model. Also, a considerable effort has been made to demonstrate the potential impacts of TOB on the strength of the $\mathrm{M}-\mathrm{H}$, the unmodifiedrecalibrated $\mathrm{B}-\mathrm{C}$, and the modified $\mathrm{B}-\mathrm{C}$ model and their accuracy of estimates. Therefore, future studies should take this factor into consideration during model development and application.

The $\mathrm{M}-\mathrm{H}$ model selection procedure was quite extensive compared with the original B-C (Bristow and Campbell, 1984), the recalibrated B-C (Goodin et al., 1999), and the modified B-C (Goodin et al., 1999) models. The above studies developed one model and subsequently applied it to a number of sites for performance evaluation. In the present study, 27 sets of coefficients were developed initially, with nine sets for each reporting time. As noted previously, nine sets of coefficients were adopted for the M-H model based on their performance with midnight-to-midnight observation data. The M-H model with these nine sets of coefficients was applied to all nine stations, including the originating site, to estimate solar radiation. Afterward, model performances were evaluated for all 81 applications, and the $\mathrm{M}-\mathrm{H}$ model with one set of coefficients was selected. It is true that the unmodified-recalibrated B-C model performed slightly superior to the $\mathrm{M}-\mathrm{H}$ model for its application to the NGP. However, based on our study conditions, and its greater stability, it can be said that the M-H model selection procedure is more thorough and accurate.

\section{SUMMARY}

This study presents and evaluates three models for estimating solar radiation in the NGP. These include a new model $(\mathrm{M}-\mathrm{H})$, the unmodified-recalibrated B-C model (Goodin et al., 1999), and the modified B-C model (Goodin et al., 1999). These models require the measured DR to estimate solar radiation. Potential bias associated with the reporting time of air temperature and its impacts on the solar radiation estimation was also assessed. Of the three reporting times $(0800,1600$, and $2400 \mathrm{~h}$ ), the models based on 2400-h observations performed best.

To select the final form of the M-H model for the NGP, nine sets of site-specific solar radiation estimation coefficients using data with 2400 -h reporting time were compared. The M-H model with each of these sets of coefficients was applied to all nine sites, and their performance was evaluated. The M-H model based on coefficients formulated from Akron, $\mathrm{CO}$, was selected for the whole region. The core strength of this model and the coefficients was that it performed relatively satisfactorily for all sites, irrespective of cloudiness of the site. It is important to note that the model underestimated high values. After selection of the $\mathrm{M}-\mathrm{H}$ model and its coefficients, it was compared to the unmodified-recalibrated B-C (Goodin et al., 1999) and modified B-C models (Goodin et al., 1999). The model evaluation statistics show that the unmodified B-C model (RMSE range $=3.53-4.78 \mathrm{MJ} \mathrm{m}^{-2} \mathrm{~d}^{-1}, D$ index range $=0.94$ 0.91 , and relative error range $=20-36 \%$ ) performs slightly better than the $\mathrm{M}-\mathrm{H}$ model (RMSE range = $3.90-4.93 \mathrm{MJ} \mathrm{m}^{-2} \mathrm{~d}^{-1}, D$ index range $=0.94-0.91$, and relative error range $=22-37 \%$ ) proposed here, and both of these models are quite superior compared with the modified B-C model (RMSE range $=7.06-9.16 \mathrm{MJ} \mathrm{m}^{-2}$ $\mathrm{d}^{-1}, D$ index range $=0.67$ to 0.56 , and relative error range $=45$ to $62 \%$ ). Both forms of the $\mathrm{B}-\mathrm{C}$ models underestimate high values like the $\mathrm{M}-\mathrm{H}$ model. Results also indicated that performance of the unmodifiedrecalibrated B-C model was relatively better at less cloudy sites. Overall, the $\mathrm{M}-\mathrm{H}$ model shows greater stability for varied climatic conditions compared with the other two models.

\section{ACKNOWLEDGMENTS}

The authors thank Dr. R.M. Caldwell and Dr. M.J. Hayes for their valuable comments and suggestions during prepara- 
tion of this manuscript. Thanks also go to the three reviewers, the associate editor, and the technical editor for their insightful suggestions that further improved this paper. Technical assistance provided by Sebastien Korner during preparation of Figure 1 is much appreciated.

\section{REFERENCES}

Aceves-Navarro, L.A., K.G. Hubbard, and J.J. Schmidt. 1989. Group calibration of silicon cell pyranometers for use in an automated network. J. Atmos. Oceanic Technol. 6:875-879.

Atwater, M.A., and J.T. Ball. 1978. A numerical solar radiation model based on standard meteorological observations. Sol. Energy 21: 163-170.

Baker, D.G. 1975. Effect of observation time on mean temperature estimation. J. Appl. Meteorol. 14:471-476.

Blackburn, T. 1983. A practical method of correcting monthly average temperature biases resulting from differing times of observation. J. Clim. Appl. Meteorol. 22:328-330.

Bristow, K.L., and G.S. Campbell. 1984. On the relationship between incoming solar radiation and daily maximum and minimum temperature. Agric. For. Meteorol. 31:159-166.

Cengiz, H.S., J.M. Gregory, and J.L. Seabaugh. 1981. Solar radiation prediction from other climate variables. Trans. ASAE 24: $1269-1272$.

Clemence, B.S.E. 1992. An attempt at estimating solar radiation at South African sites which measure air temperature only. S. Afr. Tydskr. Plant Grond 9:40-42.

DeGaetano, A.T. 1999. A method to infer observation time based in day-to-day temperature variations. J. Clim. 12:3443-3456.

Dissing, D., and G. Wendler. 1998. Solar radiation climatology of Alaska. Theor. Appl. Climatol. 61:161-175.

Easterling, W.E., III, P.R. Crosson, N.J. Rosenberg, M.S. McKenny, L.A. Katz, and L. Lemon. 1993. Agricultural impacts of and responses to change in the Missouri-Iowa-Nebraska-Kansas (MINK) region. Clim. Change 24:23-61.

Goodin, D.G., J.M.S. Hutchinson, R.L. Vanderlip, and M.C. Knapp. 1999. Estimating solar irradiance for crop modeling using daily air temperature data. Agron. J. 91:845-851.

Hook, J.E., and R.W. McClendon. 1992. Estimation of solar radiation data missing from long-term meteorological record. Agron. J. 84 739-742.

Hubbard, K.G., N.J. Rosenberg, and D.C. Nielsen. 1983. An automated weather data network in support of agricultural operations. J. Water Resour. Plann. Manage. 109:213-222.
Hunt, L.A., L. Kuchar, and C.J. Swanton. 1998. Estimation of solar radiation for use in crop modeling. Agric. For. Meteorol. 91: 293-300.

Janis, M. 2000. Errors in daily minimum and maximum temperature induced by observation time. p. 74-77. Proc. Conf. on Appl. Climatol., 12th, Asheville, NC. 8-11 May 2000. The Am. Meteorol. Soc., Boston.

Karl, T.R., C.N. Williams, Jr., and P.J. Young. 1986. A model to estimate the time of observation bias associated with monthly mean maximum, minimum, and mean temperatures for the United States. J. Clim. Appl. Meteorol. 24:1383-1387.

Legates, D.R., and G.J. McCabe, Jr. 1999. Evaluating the use of "goodness-of-fit" measures in hydrologic and hydroclimatic model validation. Water Resour. Res. 35:233-241.

List, R.J. 1951. Smithsonian meteorological tables. Smithsonian Inst., Washington, DC.

Mahmood, R., and J.T. Hayes. 1995. A model-based assessment of impacts of climate change on the boro rice yield in Bangladesh. Phys. Geogr. 16:463-86.

Mearns, L.O., C. Rosenzweig, and R. Goldberg. 1996. The effect of changes in daily and inter-annual climatic variability on CERES Wheat: A sensitivity study. Clim. Change 32:257-292.

McVicar, T.R., and D.L.B. Jupp. 1999. Estimating one-time-of-day meteorological data as inputs to thermal remote sensing based energy balance models. Agric. For. Meteorol. 96:219-238.

National Climatic Data Center. 1995. Cooperative summary of day, dataset TD 3200. U.S. Dep. of Commerce, Natl. Oceanic and Atmos. Administration, Natl. Climatic Data Cent., Ashville, NC

Oke, T.R. 1987. Boundary layer climates. Methuen and Co., New York.

Rosenberg, N.J., B.L. Blad, and S.B. Verma. 1983. Microclimate: The biological environment. John Wiley \& Sons, New York.

Rosenzweig, C., and M.L. Parry. 1994. Potential impact of climate change on world food supply. Nature 367:133-138.

Schaal, L.A., and R.F. Dale. 1977. Time of observation temperature bias and "climate change." J. Appl. Meteorol. 16:215-222.

Thornton, P.E., and S.W. Running. 1999. An improved algorithm for estimating incident daily solar radiation from measurements of temperature, humidity, and precipitation. Agric. For. Meteorol. 93 $211-228$

U.S. Naval Observatory. 1946. Tables of sunrise, sunset and twilight Supplement to the American ephemeris, 1945. U.S. Naval Observatory, Washington, DC

Willmott, C.J. 1981. On the validation of models. Phys. Geogr. 2: 184-194.

Winkler, J.A., R.H. Skaggs, and D.G. Baker. 1981. Effects of temperature adjustments on the Minneapolis-St. Paul urban heat-island. J. Appl. Meteorol. 20:1295-1300. 